Rev. Bras. Saúde Prod. Anim., Salvador, v.14, n.1, p.161-176 jan./mar., 2013 http://www.rbspa.ufba.br ISSN 15199940

\title{
Associação de probióticos adicionados à dieta de leitões no aleitamento e na creche: índices zootécnicos e economicidade ${ }^{1}$
}

\author{
Probiotics association added to piglets' diets in lactation and nursery: technical and \\ economic evaluation
}
AFONSO, Esther Ramalho ${ }^{2 *}$; PARAZZI, Larissa José2; MARINO, Carolina Tobias ${ }^{2}$; MARTINS, Simone Maria Massami Kitamura ${ }^{3}$; SILVA, Claudia Cassimira ${ }^{4}$; GAMEIRO, Augusto Hauber²; MORETTI, Aníbal de Sant'Anna ${ }^{2}$

\author{
${ }^{1}$ Parte da dissertação do primeiro autor \\ ${ }^{2}$ Universidade de São Paulo, Faculdade de Medicina Veterinária e Zootecnia, Departamento de Nutrição e \\ Produção Animal, Pirassununga,São Paulo, Brasil. \\ ${ }^{3}$ Universidade de São Paulo, Faculdade de Medicina Veterinária e Zootecnia, Departamento de \\ Reprodução Animal, Pirassununga, São Paulo, Brasil. \\ ${ }^{4}$ Universidade de São Paulo, Faculdade de Zootecnia e Engenharia de Alimentos, Pirassununga, São \\ Paulo, Brasil. \\ *Endereço para correspondência: afonsoer@usp.br
}

\section{RESUMO}

O experimento foi realizado com o objetivo de investigar efeitos zootécnicos e econômicos da associação de probióticos adicionados à dieta de leitões no aleitamento e na creche. Foram utilizados 144 leitões do nascimento até os 62 dias de idade. No aleitamento o delineamento foi inteiramente casualizado com dois tratamentos: Controle e Probiótico A. Na creche, foram blocos casualizados com arranjo fatorial de tratamentos 2x3: Probiótico A e Probiótico B; Controle e Probiótico B; Probiótico A e Probiótico A; Controle e Controle; Probiótico A e animais desafiados; e Controle e animais desafiados. Aos 35 dias de idade 48 animais da creche foram inoculados com Salmonella Typhimurium via oral. Avaliou-se peso médio, consumo médio de ração, o ganho de peso médio e a conversão alimentar. Para a análise econômica, calcularam-se os custos das dietas durante a creche e o desempenho da receita de comercialização dos animais. O consumo de ração utilizado na análise corresponde àquele ocorrido no período total de 21 a 62 dias de idade. Na maternidade não foi observado efeito nos parâmetros avaliados. Na creche, a conversão alimentar foi favorável ao tratamento Probiótico A Probiótico A. $\mathrm{Na}$ avaliação econômica o tratamento Controle Probiótico B apresentou menor custo em relação aos demais, podendo, assim, representar uma alternativa satisfatória.

Palavras-chave: Bacillus subtilis, Bifidobacterium pseudolongum, Lactobacillus reuteri.

\section{SUMMARY}

The aim of this study was to investigate the effects of probiotics association added to piglets diets in lactation and nursery. A total of 144 piglets from birth to 62 days old were raised. The design with two treatments (Control and Probiotic A) was totally randomized in lactation. In the nursery, randomized blocks with factorial arrangement $2 \times 3$ were defined: Probiotic A and Probiotic B; Control and Probiotic B; Probiotic A and Probiotic A; Control and Control; Probiotic A with challenged animals; and Control and challenged animals. At 35 days from birth 48 animals of the nursery were orally inoculated with Salmonella Typhimurium. Average weight, feed consumption, average weight gain and feed conversion were assessed. For economic analysis, the costs of diet during the nursery and income of animal's sale were calculated. Feed consumption considered for analysis was the one related to the period of 21 to 62 days of life. No effect was observed on evaluated parameters in the maternity. Positive effect was observed on feed conversion for Probiotic A and Probiotic A treatment in nursery. In economic evaluation, Control and Probiotic B treatment showed lower cost compared to other ones, thus representing a satisfactory alternative.

Keywords: Bacillus subtilis, Bifidobacterium pseudolongum, Lactobacillus reuteri 
Rev. Bras. Saúde Prod. Anim., Salvador, v.14, n.1, p.161-176 jan./mar., 2013 http://www.rbspa.ufba.br ISSN 15199940

\section{INTRODUÇÃO}

O desmame dos leitões é considerado o momento mais crítico no sistema intensivo de produção. A situação crítica do desmame é primeiramente nutricional, que gera mudança na flora, que associada ao estresse da mudança de ambiente, sociabilidade e diferenciação da pressão de infecção, gera queda da resposta imune e consequentemente maior susceptibilidade a agentes infecciosos (ALEXOPOULOS et al., 2004).

A utilização indiscriminada de promotores do crescimento (antibióticos e quimioterápicos) empregados na suinocultura vem sendo questionada por proporcionar a possível seleção de cepas resistentes, toxidade ou alergias em seres humanos (FUKAYAMA et al., 2005). Apesar da comprovada capacidade de melhorar o desempenho, quando ministrados em doses subterapêuticas, a sua utilização foi proibida pelos países da União Europeia desde 2006 (BUTAYE et at., 2003). Essas proibições geraram consequências econômicas importantes na cadeia produtiva da carne suína (BUTOLO, 2002).

Diante dessa exigência, a produção animal vem procurando adaptar-se a novas possibilidades de substituição dos antimicrobianos por outros aditivos alimentares como os prebióticos, probióticos, simbióticos, ácidos orgânicos e extratos vegetais. Assim, neste estudo propôs-se investigar os efeitos da associação de probióticos adicionados à dieta de leitões no aleitamento e na creche, por meio da análise de desempenho e da avaliação econômica relacionada ao custo com as rações e à receita com a comercialização dos animais tratados com probióticos, comparado a animais que não receberam antibióticos ou qualquer outro aditivo.

\section{MATERIAL E MÉTODOS}

O experimento foi realizado no Laboratório de Pesquisa em Suínos (LPS), da Faculdade de Medicina Veterinária e Zootecnia (FMVZ) da Universidade de São Paulo, Campus de Pirassununga SP. Foram utilizados 144 leitões híbridos na fase de aleitamento e creche, provenientes de 24 matrizes da empresa de genética Pen Ar Lan, situada em Espírito Santo do Pinhal SP.

Na maternidade utilizou-se delineamento inteiramente casualizado composto por dois tratamentos: Controle (CTL) e Probiótico A (ProbA). As fêmeas utilizadas eram primíparas. Não se adotou a sincronização de parto sendo que esses ocorreram em sua totalidade no período da madrugada, com auxilio das pessoas envolvidas no experimento. A unidade experimental foi a gaiola de parição. A distribuição dos tratamentos foi intercalada somente dentro de cada sala de maternidade, onde o probiótico (ProbA) foi fornecido aos leitões antes da mamada do colostro. O mesmo procedimento foi realizado com o tratamento controle, intercalando-se assim com o tratamento ProbA. Esta adequação teve como objetivo uniformizar os tratamentos na sala de maternidade. A homogeneização da leitegada foi realizada apenas em situações específicas tais como na ocorrência de excesso de leitões de ou de baixo número de tetos funcionais, ou na substituição de leitões mortos por esmagamento por animais pertencentes a leitegadas grandes. Tal procedimento foi realizado em até três dias de vida para evitar a recusa dos leitões pela porca. Houve cuidado de homogeneizar apenas leitões de mesmo tratamento.

O Probiótico A utilizado foi um produto comercial em pó composto por Lactobacillus reuteri $\left(1,5 \times 10^{9} \mathrm{UFC} / \mathrm{g}\right) \mathrm{e}$ Bifidobacterium pseudolongum 
$\left(1,5 \times 10^{9} \mathrm{UFC} / \mathrm{g}\right) . \quad \mathrm{O}$ tratamento $\mathrm{CTL}$ corresponde ao fornecimento de água destilada. A dose do probiótico foi previamente preparada quando iniciado o parto, misturando-se o conteúdo do envelope do probiótico de $5 \mathrm{~g}$ em $15 \mathrm{~mL}$ de água destilada. Foi administrado, para 72 leitões, $1 \mathrm{~mL}$ de probiótico. Para os outros 72 leitões restantes foi administrado $1 \mathrm{~mL}$ de água destilada (CTL), sendo ambos procedimentos via oral. Aos 21 dias de idade, o mesmo procedimento foi realizado, em que a mesma dose nos dois tratamentos foi administrada aos leitões. Em relação a este procedimento de administração do probiótico e água destilada, os leitões foram cuidadosamente imobilizados e, através de uma seringa, receberam o produto diretamente via oral, na proximidade do esôfago. Com este método procurou-se evitar qualquer desperdício. Todavia, caso tenha acontecido alguma perda, a mesma não foi controlada.

As variáveis analisadas na fase de maternidade foram: peso médio (PM) em quilogramas $(\mathrm{kg})$ ao nascimento, 7 ; 14 e 21 dias de idade; e o ganho médio diário de peso (GMDP) em $\mathrm{kg} /$ animal/dia, do nascimento aos 7 , dos 8 aos 14 e dos 15 aos 21 dias de idade.

$\mathrm{Na}$ creche, o delineamento experimental foi em blocos casualizados em função do peso dos animais. Antes de os leitões serem transferidos para unidade de creche, foram pesados individualmente. A partir de então, os pesos dos animais foram ranqueados. Na sequência, os leitões foram divididos em animais pesados, médios e leves, levando em consideração os seguintes parâmetros: pesados (de 8,0 a 9,0kg); médios (de 6,0 a 7,9kg) e leves (de 5,0 a 5,9kg). Assim, procurou-se conferir maior uniformidade em cada baia, com arranjo fatorial de tratamentos $2 \times 3$. A unidade experimental considerada foi a baia com três animais, constituindo 8 repetições por tratamento, sendo baia de machos e baia de fêmeas.

Os 144 leitões da maternidade foram divididos a partir dos dois tratamentos ProbA e CTL e distribuídos em 3 salas de creche, formando assim 6 tratamentos: na sala 1, o tratamento com Probiótico A e Probiótico B (ProbA ProbB) e o tratamento Controle Probiótico B (CTL ProbB); na sala 2, o tratamento Probiótico A e Probiótico A (ProbA ProbA) e o Controle Controle (CTL CTL); e na sala 3, Probiótico A Desafiado (ProbA Des) e Controle Desafiado (CTL Des). O Probiótico B (ProbB) corresponde a um produto comercial composto por Bacillus subtilis $\quad\left(1,0 \times 10^{10} \mathrm{UFC} / \mathrm{g}\right), \quad \mathrm{e} \quad$ foi acrescido na ração na quantidade de $30 \mathrm{~g} /$ tonelada de ração (Tabela 1 ).

$\mathrm{Na}$ creche, foram fornecidas as rações pré-inicial (dos 21 aos 33 dias de idade); inicial 1 (dos 34 aos 54 dias de idade), e inicial 2 ( dos 55 aos 62 dias de idade). A água e a ração foram fornecidas ad libitum (Tabela 2).

Doze horas antes do desafio programado por meio da inoculação por via oral com Salmonella Typhimurium na concentração de $1,0 \times 10^{6} \mathrm{UFC} / \mathrm{mL}$ (LSS90/05), fornecida pelo Laboratório de Sanidade Suína (LSS) da FMVZUSP, os mesmos leitões do grupo ProbA e CTL na maternidade receberam via oral o probiótico e água destilada na mesma dosagem ao nascimento. O desafio foi realizado aos 35 dias de idade. Os leitões desafiados permaneceram em sala (sala 3 ) isolada das demais salas, sala 2 e sala 1, para evitar risco de contaminação cruzada. As rações de cada sala foram separadas evitando o contato entre si, bem como, todos os objetos que por ventura fossem usados no dia-a-dia do experimento, o ambiente foi totalmente controlado $\mathrm{e}$ idêntico para todas as salas. 
Rev. Bras. Saúde Prod. Anim., Salvador, v.14, n.1, p.161-176 jan./mar., 2013 http://www.rbspa.ufba.br ISSN 15199940

Tabela 1. Descrição dos tratamentos na maternidade e na creche

\begin{tabular}{cccccc}
\hline & ProbA & Maternidade & CTL \\
\hline & 72 leitões & \multicolumn{4}{c}{ 72 leitões } \\
\hline \multicolumn{3}{c}{ Creche } \\
\hline Sala 1 & STL & ProbA & CTL & ProbA & CTL \\
\hline ProbA & ProbB & ProbA & CTL & DES & DES \\
\hline
\end{tabular}

Tabela 2. Composição das rações experimentais administradas durante o período de creche

\begin{tabular}{lccc}
\hline \multirow{2}{*}{ Ingredientes (kg) } & \multicolumn{3}{c}{ Rações Experimentais } \\
\cline { 2 - 4 } & Pré-inicial* & Inicial I* & Inicial II* \\
\hline Farelo de soja & 333,32 & 333,80 & 328,00 \\
Farelo de bolacha & 120,00 & 60,00 & - \\
Milho moído & - & - & 598,00 \\
Milho fubá & 428,64 & 533,52 & - \\
Soro de leite & 40,00 & 10,00 & - \\
Fosfato bicálcico & 16,00 & 15,00 & 18,50 \\
Calcáreo calcítico & - & 5,40 & 7,00 \\
Lactose & 12,00 & 4,00 & - \\
Açúcar & 30,00 & 30,00 & 40,00 \\
Cloreto de sódio & 3,20 & 2,60 & 6,00 \\
Lisina & 2,80 & 1,40 & \\
Metionina & 3,60 & 1,00 & - \\
Fitase & 0,12 & 0,06 & - \\
Colina & 0,32 & 0,22 & - \\
Palatabilizante & 8,00 & 1,00 & - \\
Premix Vitamínico** & 2,00 & 1,00 & 1,00 \\
Premix Mineral *** & - & 1,00 & 1,50 \\
\hline Batida Total (kg) & 1000 & 1000 & 1000 \\
\hline & \multicolumn{3}{c}{ Composição Nutricional } \\
\hline Matéria seca (\%) & 89,66 & 89,62 & 90,21 \\
Energia bruta (cal/g) & 4341 & 4303 & 4282 \\
Proteína bruta (\%) & 21,62 & 22,46 & 21,94 \\
Fibra bruta (\%) & 3,55 & 3,38 & 5,07 \\
Matéria mineral (\%) & 5,26 & 6,19 & 7,41 \\
Cálcio (\%) & 0,58 & 0,93 & 0,94 \\
Fósforo (\%) & 0,52 & 0,67 & 0,62 \\
Extrato Etéreo (\%) & 2,68 & 2,68 & 3.13 \\
\hline *Ir & & & \\
\hline
\end{tabular}

*Inclusão de probiótico: $30 \mathrm{~g} /$ tonelada de ração dependendo do tratamento administrado.

**Suplementação vitamínica para cada $1,5 \mathrm{~kg}$ do produto (Rovimix ${ }^{\circledR}, \mathrm{DSM}$ ): selênio $300 \mathrm{mg} / \mathrm{kg}$; Vit A $10.000 \mathrm{UI} / \mathrm{g}$; Vit $\mathrm{D}_{3} 2.000 \mathrm{UI} / \mathrm{g}$; Vit E $50.000 \mathrm{mg} / \mathrm{kg} ;$ Vit $\mathrm{K}_{3} 2.000 \mathrm{mg} / \mathrm{kg} ;$ Vit $\mathrm{B}_{1} 2.000 \mathrm{mg} / \mathrm{kg} ;$ Vit $_{2}$ $6.000 \mathrm{mg} / \mathrm{kg}$; Vit $B_{6} 3.000 \mathrm{mg} / \mathrm{kg}$; Vit $B_{12} 30.000 \mathrm{mg} / \mathrm{kg}$; niacina $30.000 \mathrm{mg} / \mathrm{kg}$; ácido pantotênico $15.000 \mathrm{mg} / \mathrm{kg}$; ácido fólico $3.000 \mathrm{mg} / \mathrm{kg}$; biotina $200.000 \mathrm{mcg} / \mathrm{kg}$.

***Suplementação mineral para cada $1 \mathrm{~kg}$ do produto (Roligomix $\left.{ }^{\circledR}, \mathrm{DSM}\right)$ : ferro $100.000 \mathrm{mg} / \mathrm{kg}$; cobre $20.000 \mathrm{mg} / \mathrm{kg}$; zinco $100.000 \mathrm{mg} / \mathrm{kg}$; manganês $40.000 \mathrm{mg} / \mathrm{kg}$; iodo $1.500 \mathrm{mg} / \mathrm{kg}$. 
As variáveis de desempenho analisadas foram peso médio (PM) aos 34 (Período 1), 47 (Período 2), 54 (Período 3), 62 (Período 4) dias de idade. As faixas de consumo de ração médio diário (CRMD) em kg/animal/dia, ganho de peso médio diário (GPMD) em $\mathrm{kg} /$ animal/dia e conversão alimentar (CA) consideradas foram dos 21 aos 33 dias (Período 1), 34 aos 47 dias (Período 2), 48 aos 54 dias (Período 3), 55 aos 62 dias (Período 4) e durante o período total.

A análise econômica foi baseada no consumo de ração de cada tratamento, bem como o quanto foi gasto com probiótico na fase de creche. $O$ consumo de ração utilizado na análise disse respeito àquele ocorrido no período total de 21 a 62 dias de idade, sendo Probiótico A e Probiótico B (ProbA ProbB) 0,773kg, tratamento Controle Probiótico B (CTL ProbB) 0,669kg, Probiótico A e Probiótico A (ProbA ProbA) 0,760kg, Controle Controle (CTL CTL) 0,708kg, Probiótico A Desafiado (ProbA Des) $0,899 \mathrm{~kg}$ e Controle Desafiado (CTL Des) $0,896 \mathrm{~kg}$. Os preços do suíno vivo foram obtidos junto ao Centro de Estudos Avançados em Economia Aplicada (CEPEA/ESALQ/USP) para o mês de dezembro de 2010. Os custos das rações foram obtidos por meio de cotações junto a empresas fornecedoras, referentes ao mesmo mês. As fórmulas utilizadas para os cálculos econômicos de cada tratamento foram: Receita total $(\mathrm{RT})=[$ (peso vivo médio $\mathrm{x}$ número de animais por tratamento) $\mathrm{x}$ preço do $\mathrm{kg}$ vivo]; e Custo total da dieta (CTD) = (custo da ração + custo do aditivo). Com esses valores calcularam-se: a Margem bruta do lote (MB): RT CTD; a Relação custo dieta/receita total (Re): CTD / RT; a Participação do custo do aditivo sobre o custo total da dieta (PAD): custo do aditivo/CTD; e a
Participação do custo do aditivo sobre a receita total (PAR): custo do aditivo/RT.

Foram realizadas comparações entre o controle versus os demais tratamentos. Para essas comparações, calculou-se a variação percentual do tratamento em relação ao controle para o custo total da dieta (CTD), a variação percentual da receita total (RT) e a variação das margens por quilo, utilizando as seguintes fórmulas: (CTDa - $\mathrm{CTDb}$ ) / $\mathrm{CTDb}$; $(\mathrm{RTa}-\mathrm{RTb}) / \mathrm{RTb}$ e $(\mathrm{MBa}-$ $\mathrm{MBb}) / \mathrm{MBb}$, respectivamente. Sendo "a" referente ao tratamento em análise e "b" referente ao controle.

Os dados foram analisados por meio do programa computacional Statistical Analysis System (SAS Institute, 2008), sendo anteriormente verificada a normalidade dos resíduos pelo teste de Shapiro-Wilk (PROC UNIVARIATE). Os dados referentes ao desempenho foram submetidos à análise de variância, que separou como fontes de variação o efeito de bloco e o efeito de tratamento, sendo adicionado, ainda, o fator medidas repetidas no tempo (período), referentes aos diferentes períodos de desenvolvimento dos animais. No modelo, o efeito de tratamento foi considerado fixo e os efeitos de bloco e período e suas interações, aleatórios. Tal análise foi realizada utilizando-se o procedimento MIXED do SAS. A análise por tempo somente foi realizada quando as interações entre efeito de tempo e efeito de tratamento foram significativas. Os tratamentos foram decompostos pelo uso de contrastes ortogonais: Contraste 1 (C1): efeito da administração do ProbA versus a não administração do ProbA; Contraste 2 (C2): efeito da adição do ProbB na ração versus a não administração do ProbB na ração; Contraste 3 (C3): efeito do Desafio (DES) versus Controle (CTL); 
Rev. Bras. Saúde Prod. Anim., Salvador, v.14, n.1, p.161-176 jan./mar., 2013 http://www.rbspa.ufba.br ISSN 15199940

Contraste 4 (C4): interação da administração do probiótico ProbA com a adição do ProbB na ração; e Contraste
5 (C5): interação da administração do ProbA com o Desafio (Tabela 3).

Tabela 3. Composição dos tratamentos e descrição dos contrastes ortogonais

\begin{tabular}{lcccccc}
\hline \multirow{2}{*}{ Item } & Trat 1 & Trat 2 & Trat 3 & Trat 4 & Trat 5 & Trat 6 \\
\cline { 2 - 7 } & \multirow{2}{*}{ ProbA ProbB } & CTL & \multirow{2}{*}{ ProbA ProbA } & $\begin{array}{c}\text { CTL } \\
\text { CTL }\end{array}$ & $\begin{array}{c}\text { ProbA } \\
\text { DES }\end{array}$ & $\begin{array}{c}\text { CTL } \\
\text { DES }\end{array}$ \\
\hline Probiótico A & $\mathrm{S}$ & $\mathrm{N}$ & $\mathrm{S}$ & $\mathrm{N}$ & $\mathrm{S}$ & $\mathrm{N}$ \\
Probiótico B & $\mathrm{S}$ & $\mathrm{S}$ & $\mathrm{N}$ & $\mathrm{N}$ & $\mathrm{N}$ & $\mathrm{N}$ \\
Desafio & $\mathrm{N}$ & $\mathrm{N}$ & $\mathrm{N}$ & $\mathrm{N}$ & $\mathrm{S}$ & $\mathrm{S}$ \\
\hline Contrastes & & & & & & \\
\hline C1: ProbA x sem ProbA & -1 & 1 & -1 & 1 & -1 & 1 \\
C2: ProbB x sem ProbB & -1 & -1 & 1 & 1 & 0 & 0 \\
C3: Desafio x Controle & 0 & 0 & -1 & -1 & 1 & 1 \\
C4: Interação ProbA*ProbB & 1 & -1 & -1 & 1 & 0 & 0 \\
C5: Interação ProbA*Desafio & 0 & 0 & 1 & -1 & -1 & 1 \\
\hline
\end{tabular}

\section{RESULTADOS E DISCUSSÃO}

$\mathrm{Na}$ fase de maternidade não foi observada interação entre tempo e os tratamentos Probiótico A e Controle $(p>0,05)$, bem como efeito de tratamento $(\mathrm{p}>0,05)$. Ao longo do período, os valores médios de peso médio foram 3,44kg (CTL) e 3,56kg Probiótico A (ProbA). Quanto ao ganho médio diário de peso, constatou-se interação entre tempo e tratamento $(\mathrm{p}=0,0318)$ no período de 0 a 7 dias de idade. Os leitões que receberam Probiótico A obtiveram ganho de peso médio diário mais elevado $(0,175$ $\mathrm{kg} /$ animal/dia) quando comparado ao controle $\quad(0,159 \mathrm{~kg} / \mathrm{animal} / \mathrm{dia})$. Nos demais períodos não foram observados efeitos significativos. Em média, durante a maternidade o ganho de peso diário foi $0,204 \mathrm{~kg} / \mathrm{animal} / \mathrm{dia}$ (CTL) e 0,212kg/animal $/$ dia (ProbA). Os resultados obtidos na maternidade revelaram-se positivo para o tratamento Probiótico A. Isso se deve, possivelmente, pela melhor condição intestinal que o probiótico deve ter oferecido pela melhor colonização de bactérias intestinais benéficas.

Por outro lado, Corrêa et al. (2010) realizou experimento em granja comercial, com administração de Lactobacillus reuteri $\left(1.5 \times 10^{9} \mathrm{UFC} / \mathrm{g}\right)$ e Bifidobacterium pseudolongum $\left(1.5 \times 10^{9} \mathrm{UFC} / \mathrm{g}\right)$ via oral antes da ingestão do colostro, não sendo observado efeito significativo para as variáveis peso médio e ganho de peso médio diário. $\mathrm{O}$ autor comenta que esses resultados ocorreram, possivelmente, devido ao "status" sanitário da granja em que foi desenvolvido o estudo. Já Abe et al. (1995), ao utilizarem colônias de Bifidobacterium pseudolongum e Lactobacillus acidophilus como probióticos em leitões na fase de aleitamento e creche, evidenciaram maior ganho de peso na fase de aleitamento.

Os resultados obtidos na maternidade são sugestivos de que a administração de probióticos, logo após o nascimento, pode ser eficaz, uma vez que ao nascimento o intestino pode já estar sendo colonizado e a bactéria probiótica 
agiria evitando que as patogênicas atapetem a mucosa intestinal e o resultado dessa ação é refletido em melhor absorção de nutrientes e imunoglobulinas do colostro, possibilitando maior viabilidade do leitão, havendo, em contrapartida, menor perda dos leitões, particularmente nos seus primeiros dias de vida (ABRAHÃO et al., 2004).

$\mathrm{Na}$ fase de creche observou-se efeito significativo da interação entre tempo e tratamento $(\mathrm{p}=0,0203)$ para variável peso médio (Tabela 4). Aos 33 dias, detectou-se efeito significativo no contraste $C 4(p=0,0203)$. No grupo que recebeu Probiótico A associado com Probiótico B, o peso médio foi mais elevado quando comparado a não associação dos dois probióticos (Figura 1). Aos 54 dias, observou-se efeito significativo no contraste $\mathrm{C} 2$ $(p=0,0484)$ onde o grupo que recebeu o Probiótico B apresentou peso médio inferior $(17,52 \mathrm{~kg})$ em relação aos tratamentos que não receberam $(19,03 \mathrm{~kg})$. No mesmo período, houve efeito significativo no $\mathrm{C} 4(\mathrm{p}=0,0210)$. Constatou-se interação entre a administração ou não do Probiótico A e adição ou no do Probiótico $\mathrm{B}$, onde a não associação de ambos os probióticos resultou em peso mais elevado (Figura 2). Aos 62 dias, houve significância no contraste $\mathrm{C} 2(\mathrm{p}=0,0049)$, evidenciando que o grupo Probiótico B apresentou menor valor $(21,68 \mathrm{~kg})$ em relação aos demais tratamentos que não receberam Probiótico B $(23,78 \mathrm{~kg})$.

Estes resultados obtidos sobre o peso médio até os 54 dias de idade demonstram que a combinação dos Probiótico A e Probiótico B levou a maior peso médio, provavelmente pela combinação entre as bactérias dos probióticos se combinarem entre si, além da melhor condição da microbiota intestinal dos animais que receberam probiótico ao nascimento e aos 21 dias de idade, gerando este resultado positivo.

Porém, aos 54 dias e nos demais, não foi observada interação, sugerindo que nesse primeiro momento, as bactérias que compunham os probióticos apresentaram uma complementação positiva na microbiota, havendo posteriormente um quadro simbiótico que não interferiu no peso.

Tabela 4. Valores médios e coeficientes de variação da variável peso médio (PM), em quilogramas, de leitões entre os 33 e 62 dias de idade, e as probabilidades dos contrastes

\begin{tabular}{|c|c|c|c|c|c|c|c|c|c|c|c|c|c|}
\hline \multirow{2}{*}{$\begin{array}{l}\text { Período } \\
\text { (dias) }\end{array}$} & \multicolumn{6}{|c|}{ Tratamentos* } & \multirow[b]{2}{*}{ Média } & \multirow[b]{2}{*}{$\mathrm{CV}^{* *}$} & \multicolumn{5}{|c|}{ Contrastes $* * *$} \\
\hline & $\begin{array}{l}\text { ProbA } \\
\text { ProbB }\end{array}$ & $\begin{array}{c}\text { CTL } \\
\text { ProbB }\end{array}$ & $\begin{array}{l}\text { ProbA } \\
\text { ProbA }\end{array}$ & $\begin{array}{l}\text { CTL } \\
\text { CTL }\end{array}$ & $\begin{array}{c}\text { ProbA } \\
\text { DES }\end{array}$ & $\begin{array}{l}\text { CTL } \\
\text { DES }\end{array}$ & & & 1 & 2 & 3 & 4 & 5 \\
\hline 33 & 9,50 & 8,88 & 8,87 & 9,43 & 8,99 & 9,76 & 9,24 & 18,17 & NS\# & NS & NS & 0,0203 & NS \\
\hline 47 & 14,38 & 12,78 & 14,95 & 14,30 & 13,60 & 14,80 & 14,14 & 18,22 & NS & NS & NS & NS & NS \\
\hline 54 & 18,57 & 16,47 & 18,29 & 19,78 & 18,48 & 18,80 & 18,40 & 17,43 & NS & 0,0484 & NS & 0,0210 & NS \\
\hline 62 & 22,59 & 20,78 & 23,92 & 23,64 & 23,47 & 23,63 & 23,01 & 14,54 & NS & 0,0049 & NS & NS & NS \\
\hline
\end{tabular}

Probabilidade interação tempo e tratamento $(\mathrm{p}=0,0203)$.

*Tratamentos: ProbA ProbB; CTL ProbB; ProbA ProbA; CTL CTL; ProbA DES; CTL DES.

\#NS: Não significativo.

**Coeficiente de variação

***Contrastes: C1: efeito da administração do ProbA versus a não administração do ProbA; C2: efeito da adição do ProbB na ração versus a não administração do ProbB na ração; C3: efeito do Desafio (DES) versus Controle (CTL); C4: interação da administração do probiótico ProbA com a adição do ProbB na ração; C5: interação da administração do ProbA com o Desafio (DES). 
Rev. Bras. Saúde Prod. Anim., Salvador, v.14, n.1, p.161-176 jan./mar., 2013 http://www.rbspa.ufba.br ISSN 15199940

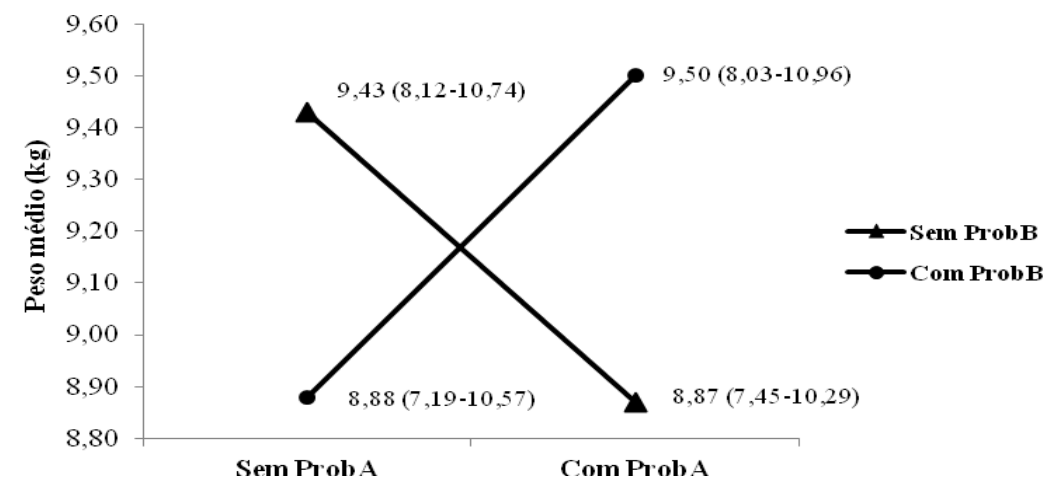

Figura 1. Médias e intervalos de confiança $95 \%$ da interação do peso médio entre os probióticos $\mathrm{A}$ e $\mathrm{B}$ aos 33 dias de idade $(\mathrm{p}=0,0203)$

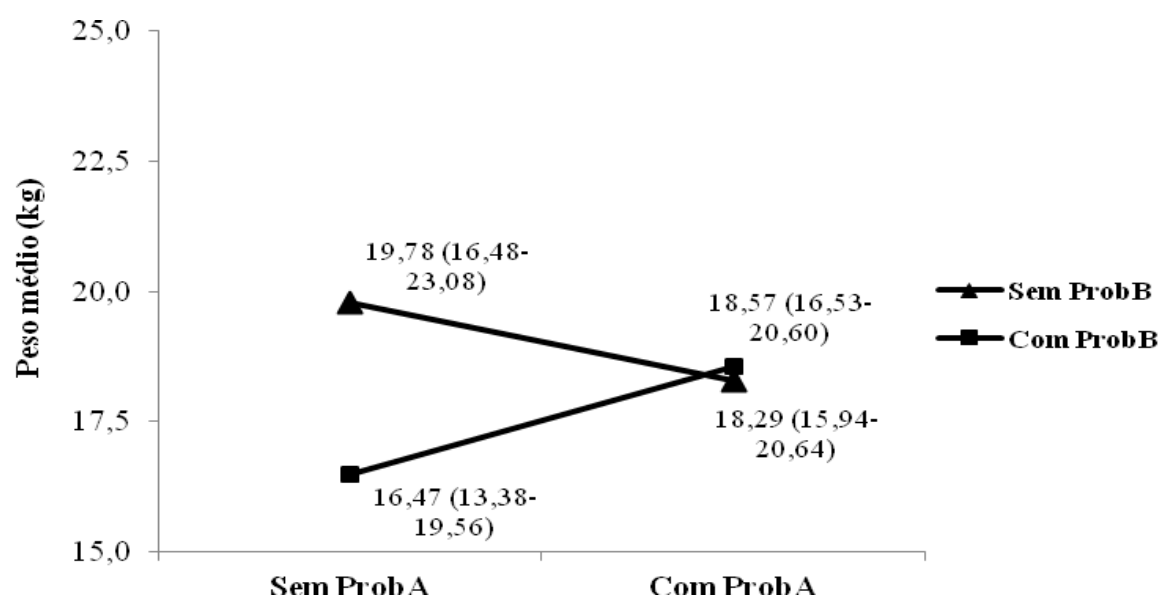

Figura 2. Médias e intervalos de confiança $95 \%$ da interação do peso médio entre os probióticos $\mathrm{A}$ e $\mathrm{B}$ aos 54 dias de idade $(\mathrm{p}=0,0210)$

Quanto ao consumo médio diário de ração (Tabela 5), foi observado efeito significativo da interação entre tempo e tratamento $(\mathrm{p}=0,0098)$. No período de 21 a 33 dias, observou-se efeito significativo no contraste $\mathrm{C} 4(\mathrm{p}=0,0281)$, sendo que o tratamento Probiótico B associado com Probiótico A obteve maior consumo em relação aos demais tratamentos (Figura 3). Ao analisar o período de 48 a 54 dias, foi observado efeito significativo para o contraste C3 $(p<0001)$. O grupo que recebeu Probiótico A obteve maior consumo
$(0,960 \mathrm{~kg} / \mathrm{animal} / \mathrm{dia})$ em relação aos tratamentos que não receberam Probiótico A $(0,848 \mathrm{~kg} / \mathrm{animal} / \mathrm{dia})$. Os tratamentos desafiados obtiveram maior consumo $(1,270 \mathrm{~kg} / \mathrm{animal} / \mathrm{dia})$ em relação ao grupo controle $(0,670 \mathrm{~kg} / \mathrm{animal} / \mathrm{dia})$ Houve significância nos contrastes $\mathrm{C} 1$ e $\mathrm{C} 2$, no período de 55 a 62 dias, evidenciando nos tratamentos que receberam Probiótico A maior consumo $(1,240 \mathrm{~kg} / \mathrm{animal} / \mathrm{dia})$ em relação aos tratamentos que não receberam Probiótico $\mathrm{A}$ $(1,161 \mathrm{~kg} / \mathrm{animal} / \mathrm{dia}) \quad(p=0,0345)$. Já no 
Rev. Bras. Saúde Prod. Anim., Salvador, v.14, n.1, p.161-176 jan./mar., 2013 http://www.rbspa.ufba.br ISSN 15199940

contraste C2, observou-se que os tratamentos que receberam Probiótico B $(1,089 \mathrm{~kg} / \mathrm{animal} / \mathrm{dia})$ obtiveram menor consumo em comparação ao controle $(1,240 \mathrm{~kg} / \mathrm{animal} / \mathrm{dia})-(\mathrm{p}=0,0113)$.

Tabela 5. Valores médios e coeficientes de variação da variável consumo médio diário de ração (CMDR), em quilogramas/animal/dia, de leitões entre os 21 e 62 dias de idade, e a probabilidade dos contrastes

\begin{tabular}{|c|c|c|c|c|c|c|c|c|c|c|c|c|c|}
\hline \multirow{2}{*}{$\begin{array}{l}\text { Período } \\
\text { (dias) }\end{array}$} & \multirow[b]{2}{*}{$\begin{array}{l}\text { ProbA } \\
\text { ProbB } \\
\end{array}$} & \multirow[b]{2}{*}{$\begin{array}{c}\text { CTL } \\
\text { ProbB } \\
\end{array}$} & \multicolumn{4}{|c|}{ Tratamentos* } & \multirow[b]{2}{*}{ Média } & \multirow[b]{2}{*}{$\mathrm{CV}$} & \multicolumn{5}{|c|}{ Contrastes** } \\
\hline & & & $\begin{array}{l}\text { ProbA } \\
\text { ProbA } \\
\end{array}$ & $\begin{array}{l}\text { CTL } \\
\text { CTL }\end{array}$ & $\begin{array}{c}\text { ProbA } \\
\text { DES }\end{array}$ & $\begin{array}{l}\text { CTL } \\
\text { DES }\end{array}$ & & & 1 & 2 & 3 & 4 & 5 \\
\hline $1(21-33)$ & 0,435 & 0,361 & 0,360 & 0,372 & 0,369 & 0,401 & 0,380 & 17,87 & NS\# & NS & NS & 0,0281 & \\
\hline $2(34-47)$ & 0,655 & 0,601 & 0,674 & 0,642 & 0,635 & 0,688 & 0,650 & 13,02 & NS & NS & NS & NS & NS \\
\hline $3(48-54)$ & 0,882 & 0,658 & 0,701 & 0,640 & 1,296 & 1,245 & 0,900 & 35,68 & NS & NS & $<0001$ & NS & NS \\
\hline $4(55-62)$ & 1,119 & 1,058 & 1,305 & 1,175 & 1,295 & 1,251 & 1,200 & 14,84 & 0,0345 & 0,0113 & NS & NS & NS \\
\hline
\end{tabular}

Probabilidade interação tempo e tratamento $(\mathrm{p}=0.0098)$.

*Tratamentos: ProbA ProbB; CTL ProbB; ProbA ProbA; CTL CTL; ProbA DES; CTL DES.

\#NS: Não significativo; $C V$ = coeficiente de variação.

**Contrastes: C1: efeito da administração do ProbA versus a não administração do ProbA; C2: efeito da adição do ProbB na ração versus a não administração do ProbB na ração; C3: efeito do Desafio (DES) versus Controle (CTL); C4: interação da administração do probiótico ProbA com a adição do ProbB na ração; C5: interação da administração do ProbA com o Desafio (DES).

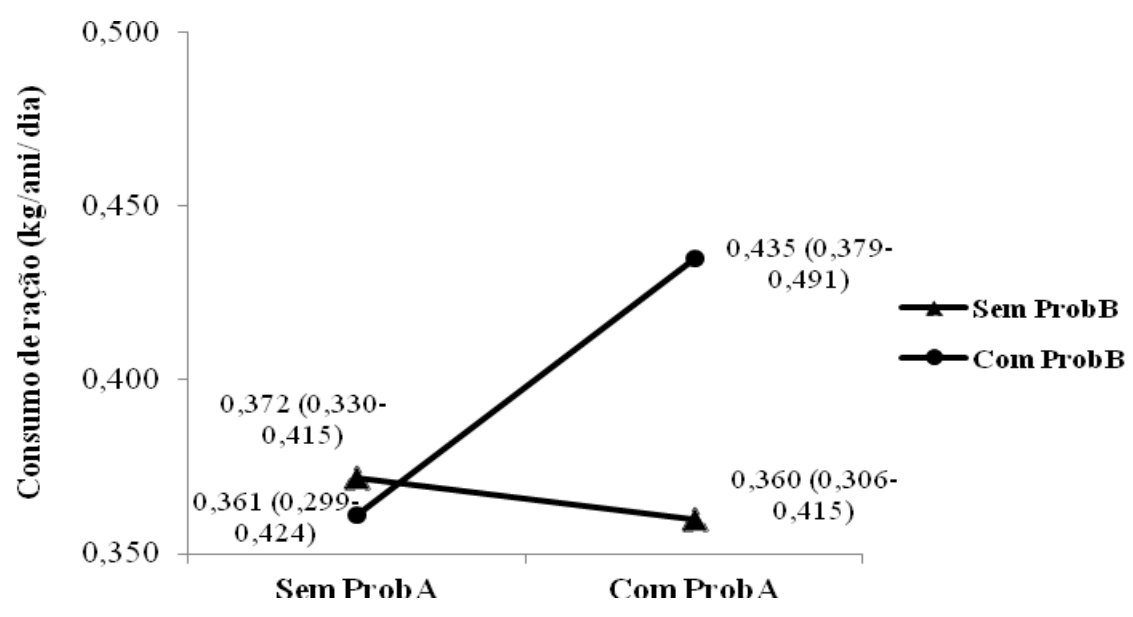

Figura 3. Médias e intervalos de confiança $95 \%$ da interação do consumo de ração entre os probióticos $\mathrm{A}$ e $\mathrm{B}$ no período de 21 a 33 dias de idade $(\mathrm{p}=0,0281)$

O desafio programado com Salmonella Typhimurium influenciou o consumo médio diário dos animais desafiados, sendo maior na semana subsequente ao desafio e esses tratamentos mostraram conversão alimentar desfavoráveis comparativamente aos não desafiados. Alguns autores relatam que existe uma redução de consumo concentrada nos três primeiros dias pós desafio 
Rev. Bras. Saúde Prod. Anim., Salvador, v.14, n.1, p.161-176 jan./mar., 2013 http://www.rbspa.ufba.br ISSN 15199940

(LOUGHMILLER et al., 2007), seguida de um acréscimo gradual que tenta compensar os valores. $\mathrm{O}$ presente estudo realizou averiguações de consumo semanal, diferentemente de Balaji et al. (2000) e Turner et al. (2001) que realizaram diariamente pós desafio, e este fato poderia ter revelado a diminuição de consumo após o desafio.

Já para o consumo na primeira semana de 21 a 33 dias, observou-se aumento dessa variável com a associação dos dois probióticos, porém vale ressaltar que este tratamento obteve maior peso médio até os 54 dias de idade, já em relação à conversão alimentar a interação da associação mostrou-se com resultado desfavorável. Estes achados são contrários aos verificados por Budiño et al. (2006), em que os animais que receberam o tratamento probiótico contendo Bacillus licheniformis e principalmente Bacillus subtillis, obtiveram menor consumo médio diário de ração em relação ao tratamento controle com dieta basal, sendo a conversão alimentar não influenciada.

Observou-se efeito significativo da interação entre tempo e tratamento $(\mathrm{p}=0,0014)$ na variável ganho médio diário de peso (Tabela 6). No período de 34 a 47 dias, constatou-se efeito significativo no contraste $\mathrm{C} 2(\mathrm{p}=0,0206)$ onde o grupo Probiótico B obteve menor ganho de peso $(0,338 \mathrm{~kg} /$ animal $/$ dia $)$ em relação aos demais tratamentos que não receberam Probiótico B $\quad(0,422 \mathrm{~kg} /$ animal $/$ dia $)$ Houve significância no contraste $\mathrm{C} 2$, no período de 55 a 62 dias, evidenciando menor ganho médio diário de peso para $\mathrm{o}$ grupo Probiótico B $(0,596 \mathrm{~kg} / \mathrm{animal} / \mathrm{dia})$ em relação aos demais tratamentos que não receberam $\mathrm{o}$ probiótico $(0,730 \mathrm{~kg} / \mathrm{animal} / \mathrm{dia})-(\mathrm{p}=0,0072)$.

Tabela 6. Valores médios e coeficientes de variação, da variável ganho médio diário de peso (GMDP), em quilogramas/animal/dia, de leitões entre os 21 e 62 dias de idade e as probabilidades dos contrastes

\begin{tabular}{|c|c|c|c|c|c|c|c|c|c|c|c|c|c|}
\hline \multirow{2}{*}{$\begin{array}{l}\text { Período } \\
\text { (dias) }\end{array}$} & \multirow[b]{2}{*}{$\begin{array}{l}\text { ProbA } \\
\text { ProbB }\end{array}$} & \multirow[b]{2}{*}{$\begin{array}{c}\text { CTL } \\
\text { ProbB }\end{array}$} & \multicolumn{4}{|c|}{ Tratamentos* } & \multirow[b]{2}{*}{ Média } & \multirow[b]{2}{*}{$\mathrm{CV}$} & \multicolumn{5}{|c|}{ Contrastes** } \\
\hline & & & $\begin{array}{l}\text { ProbA } \\
\text { ProbA }\end{array}$ & $\begin{array}{l}\text { CTL } \\
\text { CTL }\end{array}$ & $\begin{array}{c}\text { ProbA } \\
\text { DES }\end{array}$ & $\begin{array}{l}\text { CTL } \\
\text { DES }\end{array}$ & & & 1 & 2 & 3 & 4 & 5 \\
\hline $1(21-33)$ & 0,296 & 0,294 & 0,274 & 0,285 & 0,282 & 0,298 & 0,288 & 18,49 & NS\# & NS & NS & NS & NS \\
\hline $2(34-47)$ & 0,376 & 0,299 & 0,469 & 0,375 & 0,354 & 0,389 & 0,377 & 29,10 & NS & 0,0206 & NS & NS & NS \\
\hline $3(48-54)$ & 0,699 & 0,618 & 0,661 & 0,729 & 0,812 & 0,667 & 0,698 & 22,84 & NS & NS & NS & NS & NS \\
\hline $4(55-62)$ & 0,575 & 0,616 & 0,804 & 0,656 & 0,715 & 0,690 & 0,676 & 23,02 & NS & 0,0072 & NS & NS & NS \\
\hline
\end{tabular}

Probabilidade interação tempo e tratamento $(\mathrm{p}=0.0014)$.

*Tratamentos: ProbA ProbB; CTL ProbB; ProbA ProbA; CTL CTL; ProbA DES; CTL DES.

\#NS: Não significativo, $\mathrm{CV}=$ coeficiente de variação

**Contrastes: C1: efeito da administração do ProbA versus a não administração do ProbA; C2: efeito da adição do ProbB na ração versus a não administração do ProbB na ração; C3: efeito do Desafio (DES) versus Controle (CTL); C4: interação da administração do probiótico ProbA com a adição do ProbB na ração; C5: interação da administração do ProbA com o Desafio (DES).

Quanto à conversão alimentar (Tabela 7) foi observado efeito significativo da interação entre tempo e tratamento $(\mathrm{p}<0001)$. Houve significância no $\mathrm{C} 2$
( $\mathrm{p}=0,0356)$, no período de 34 a 47 dias, onde o grupo Probiótico B obteve maior conversão alimentar $(1,91)$ em relação aos demais tratamentos $(1,63)$. Já no 
Rev. Bras. Saúde Prod. Anim., Salvador, v.14, n.1, p.161-176 jan./mar., 2013 http://www.rbspa.ufba.br ISSN 15199940

período de 48 a 54 dias, no contraste C3, o grupo desafiado evidenciou maior conversão alimentar $(1,80)$ comparado ao Controle $(0,97)-(\mathrm{p}<0001)$. No período de 55 a 62 dias, observou-se efeito significativo no contraste $\mathrm{C} 4$ $(\mathrm{p}=0,0012), \quad$ sendo $\mathrm{o}$ tratamento Probiótico A não associado com Probiótico B obteve melhor conversão alimentar em relação aos demais tratamentos (Figura 4).

Tabela 7. Valores médios e coeficientes de variação da variável conversão alimentar (CA) de leitões entre os 21 e 62 dias de idade e a probabilidade dos contrastes

\begin{tabular}{|c|c|c|c|c|c|c|c|c|c|c|c|c|c|}
\hline \multirow{2}{*}{$\begin{array}{l}\text { Período } \\
\text { (dias) }\end{array}$} & \multicolumn{6}{|c|}{ Tratamentos* } & \multirow[b]{2}{*}{ Média } & \multirow[b]{2}{*}{$\mathrm{CV}$} & \multicolumn{5}{|c|}{ Contrastes** } \\
\hline & $\begin{array}{l}\text { ProbA } \\
\text { ProbB }\end{array}$ & $\begin{array}{c}\text { CTL } \\
\text { ProbB }\end{array}$ & $\begin{array}{l}\text { ProbA } \\
\text { ProbA }\end{array}$ & $\begin{array}{l}\text { CTL } \\
\text { CTL }\end{array}$ & $\begin{array}{c}\text { ProbA } \\
\text { DES }\end{array}$ & $\begin{array}{l}\text { CTL } \\
\text { DES }\end{array}$ & & & 1 & 2 & 3 & 4 & 5 \\
\hline $1(21-33)$ & 1,37 & 1,24 & 1,32 & 1,32 & 1,30 & 1,36 & 1,32 & 8,40 & NS\# & NS & NS & NS & NS \\
\hline $2(34-47)$ & 1,77 & 2,06 & 1,51 & 1,76 & 1,85 & 1,68 & 1,77 & 20,69 & NS & 0,0356 & NS & NS & NS \\
\hline $3(48-54)$ & 1,33 & 1,07 & 1,11 & 0,83 & 1,74 & 1,87 & 1,33 & 37,83 & NS & NS & $<0001$ & NS & NS \\
\hline $4(55-62)$ & 2,00 & 1,66 & 1,51 & 1,84 & 1,82 & 1,82 & 1,78 & 15,86 & NS & NS & NS & 0,0012 & NS \\
\hline
\end{tabular}

Probabilidade interação tempo e tratamento $(\mathrm{p}<0001)$.

*Tratamentos: ProbA ProbB; CTL ProbB; ProbA ProbA; CTL CTL; ProbA DES; CTL DES.

\#NS = não significativo; $\mathrm{CV}=$ coeficiente de variação.

**Contrastes: C1: efeito da administração do ProbA versus a não administração do ProbA; C2: efeito da adição do ProbB na ração versus a não administração do ProbB na ração; C3: efeito do Desafio (DES) versus Controle (CTL); C4: interação da administração do probiótico ProbA com a adição do ProbB na ração; C5: interação da administração do ProbA com o Desafio (DES).

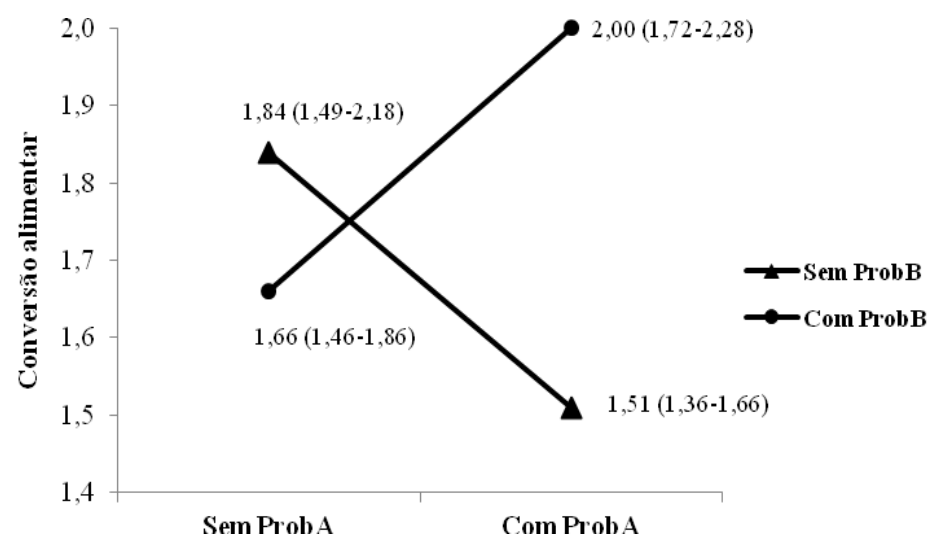

Figura 4. Médias e intervalos de confiança $95 \%$ da interação da conversão alimentar entre os probióticos A e B no período de 55 a 62 dias de idade $(\mathrm{p}=0,0012)$

No período final da creche, entre 55 a 62 dias, detectou-se melhor conversão alimentar no grupo Probiótico A. Estes resultados sugerem que os animais que receberam o Probiótico A na maternidade e 12 horas antes do desafio programado estavam em um estado favorável com a microbiota já estabelecida e estável. Silva 
et al. (2006) ao utilizarem probiótico composto por Pediococcus acidilactici associado ou não ao Bacillus subtilis, também observaram melhor conversão alimentar comparado ao grupo controle, mas não encontraram diferenças quanto ao peso final, ganho diário de peso e consumo diário de ração.

Apesar dos resultados com probióticos serem muito variáveis, Steward \& Chesson (1993) reuniram trabalhos da literatura utilizando diversos tipos de probióticos, concluindo que na média, ocorre um aumento de $4,8 \%$ no ganho de peso médio diário de leitões na fase inicial. Em um estudo realizado por Utiyama et al. (2006), utilizando Bacillus subtillis e Bacillus licheniformis, os autores observaram consumo médio diário e ganho de peso médio inferiores em todos os períodos da experimentação. Neste mesmo estudo, os autores relatam que a conversão alimentar não foi afetada pelos tratamentos, controle e probiótico. Já Abe et al. (1995), encontraram maior ganho de peso em leitões que receberam probióticos contendo Lactobacillus acidophilus e Bifidobacterium pseudolongum em relação ao tratamento controle e melhor conversão alimentar com o gênero Bifidobacterium.

Estudos realizados por Bruno (2008) e Parazzi (2010) concluíram que o desempenho dos animais tratados com extrato vegetal e probióticos, respectivamente, no período de creche foram inferiores ao tratamento contendo antimicrobiano, mas o mesmo não ocorreu para o período de crescimento e terminação, onde os tratamentos se igualaram Portanto, é possível afirmar que os probióticos acabam tendo ação a médio e longo prazo no desempenho comparado aos antimicrobianos. Os estudos citados têm levado a admitir, na linha de pesquisa empregada no Laboratório de Pesquisa em Suínos, que as averiguações com probiótico, quando avaliado o desempenho associado ou não com outros parâmetros, devem se estender para o período de crescimento e terminação para mostrar o potencial desses aditivos a serem empregados no mercado.

Em relação à análise econômica calculouse o custo da utilização de probióticos como promotores do crescimento na dieta de leitões, tentando refletir de uma maneira prática o seu uso nas granjas comerciais (Tabela 8).

Analisando o custo total da dieta (CTD), o Controle Probiótico B foi o tratamento que apresentou um valor mais baixo, seguido dos tratamentos Controle Controle e Probiótico A Probiótico A. Os demais tratamentos apresentaram custos intermediários, verificando que o tratamento Probiótico A Desafiado apresentou custo mais elevado.

Quanto à receita total do lote, o tratamento Probiótico A Probiótico A revelou maior valor, seguido dos tratamentos Controle Controle. Contudo, a relação CTD/RT mais favorável foi observada para os tratamentos Controle Controle e Controle Probiótico B.

Quanto à participação do custo do aditivo sobre o custo da dieta e da receita total, o Controle e o Desafiado não apresentam valores, pois, não foi adicionado aditivo nesses tratamentos. O tratamento Controle Probiótico B se aproxima mais do Controle, enquanto que o tratamento Probiótico A Probiótico B apresenta $12,07 \%$ do custo do aditivo em relação ao custo da dieta e $10,91 \%$ em relação à receita total, caracterizando o tratamento em que o aditivo tem maior valor sobre o custo da dieta e da receita.

Analisando as comparações a respeito da viabilidade econômica de cada tratamento, a elevação no custo da dieta - esperada devido ao acréscimo do 
Rev. Bras. Saúde Prod. Anim., Salvador, v.14, n.1, p.161-176 jan./mar., 2013 http://www.rbspa.ufba.br ISSN 15199940

custo do aditivo - precisaria ser compensada por uma elevação mais do que o proporcional na receita total, de cada tratamento em relação ao Controle, o que pode ser medido pela variação da margem bruta. Todos os tratamentos apresentaram redução da margem bruta, porém tal variação foi bastante pequena para o tratamento Controle Probiótico B (Tabela 8).

Tabela 8. Indicadores econômicos: custo total da dieta (CTD), receita total do lote (RT), relação CTD/RT, margem bruta do lote (MB), peso médio final do lote, margem bruta por quilo, participação custo do aditivo/custo dieta, participação custo do aditivo/ receita total, variação CTD (com o controle), variação RT (com o controle) e variação das margens por $\mathrm{kg}$ (com o controle)

\begin{tabular}{|c|c|c|c|c|c|c|c|}
\hline \multicolumn{2}{|l|}{ Indicador econômico } & $\begin{array}{l}\text { ProbA } \\
\text { ProbB }\end{array}$ & $\begin{array}{l}\text { CTL } \\
\text { ProbB }\end{array}$ & $\begin{array}{l}\text { ProbA } \\
\text { ProbA }\end{array}$ & $\begin{array}{l}\text { CTL } \\
\text { CTL }\end{array}$ & $\begin{array}{l}\text { ProbA } \\
\text { DES }\end{array}$ & $\begin{array}{l}\text { CTL } \\
\text { DES }\end{array}$ \\
\hline Custo total da dieta & $\mathrm{R} \$$ & $1.175,94$ & 904,75 & $1.103,46$ & 909,45 & $1.241,36$ & $1.156,44$ \\
\hline Receita total do lote & $\mathrm{R} \$$ & $1.301,18$ & $1.351,87$ & $1.377,79$ & $1.361,66$ & $1.351,87$ & $1.361,08$ \\
\hline Relação CTD/RT & $\%$ & 0,90 & 0,67 & 0,80 & 0,67 & 0,92 & 0,85 \\
\hline Margem bruta do lote & $\mathrm{R} \$$ & 125,24 & 447,12 & 274,33 & 452,21 & 110,51 & 204,64 \\
\hline Peso médio do lote & $\mathrm{kg}$ & 22,59 & 23,47 & 23,92 & 23,64 & 23,47 & 23,63 \\
\hline Margem bruta por quilo & $\begin{array}{c}\mathrm{R} \$ / \mathrm{k} \\
\mathrm{g}\end{array}$ & 0,23 & 0,79 & 0,48 & 0,80 & 0,20 & 0,36 \\
\hline $\begin{array}{l}\text { Participação custo do } \\
\text { aditivo/custo da dieta }\end{array}$ & $\%$ & 12,07 & 2,40 & 10,90 & - & 9,69 & - \\
\hline $\begin{array}{l}\text { Participação custo do } \\
\text { aditivo/receita total }\end{array}$ & $\%$ & 10,91 & 1,61 & 8,73 & - & 8,89 & - \\
\hline $\begin{array}{l}\text { Variação CTD (com o } \\
\text { controle) }\end{array}$ & $\%$ & 29,30 & $-0,52$ & 21,33 & 0,00 & 36,50 & 27,16 \\
\hline Variação RT (com o controle) & $\%$ & $-4,44$ & $-0,72$ & 1,18 & 0,00 & $-0,72$ & $-0,04$ \\
\hline $\begin{array}{l}\text { Variação da MB por kg (com o } \\
\text { controle) }\end{array}$ & $\%$ & $-71,02$ & $-0,41$ & $-40,05$ & 0,00 & $-75,39$ & $-54,73$ \\
\hline
\end{tabular}

Receita total $(\mathrm{RT})=[($ peso vivo médio $\mathrm{x}$ número de animais/tratamento $) \mathrm{x}$ preço kg vivo $]$

Custo total da dieta $(\mathrm{CTD})=(($ custo ração + custo do aditivo $) \times \mathrm{CR})$

$\mathrm{CTDa}-\mathrm{CTDb})$ / CTDb; $(\mathrm{RTa}-\mathrm{RTb})$ / RTb; $(\mathrm{MBa}-\mathrm{MBb}) / \mathrm{MBb}$. Sendo "a "referente ao tratamento e

"b" referente ao controle.

No caso, apresentou uma maior variação negativa para o tratamento Probiótico A Desafiado, segundo, com valores negativos decrescentes para, Probiótico A Probiótico B, Controle Desafiado, Probiótico A Probiótico A e, por fim igual a zero para Controle Controle.

A partir da análise econômica foi observado que o desempenho econômico do tratamento Controle Controle era esperado, pois neste tratamento não foi adicionado nenhum aditivo a dieta, reduzindo assim o seu custo, portanto o tratamento mais eficiente economicamente. $\mathrm{Na}$ sequência de economicidade verificou-se o tratamento Controle Probiótico B, seguido do Probiótico A Probiótico A.

Os preços dos probióticos refletem os custos de sua inclusão nas dietas comerciais. O preço de Probiótico A (U\$300,00/100g) caixa com 250g foi mais elevado que o custo do Probiótico B (U\$ $\$ 65,00 / \mathrm{kg})$. A análise econômica sugere que o Controle Probiótico B foi 
o mais viável dentre os tratamentos que utilizaram aditivos, pois as variações das margens brutas para seus tratamentos em relação ao tratamento controle foram inferiores. Também pode-se observar que o tratamento Probiótico A Probiótico A obteve o maior custo que o Controle Probiótico $\mathrm{B}$, porém o desempenho do Probiótico A Probiótico A foi comparativamente positivo, alcançando na variação das margens Controle Probiótico A um segundo valor, após o Controle Probiótico $\mathrm{B}$ que como foi já comentado. Quando analisado o tratamento Probiótico A Desafio observou-se que o custo é mais elevado, podendo ser justificado pelo desafio, pois estes animais apresentaram um consumo alto em relação aos demais tratamentos.

Já para no tratamento Probiótico A Probiótico $\mathrm{B}$ não houve ganho econômico viável, pois a queda na margem bruta por quilo de peso foi bastante expressiva em relação ao Controle Controle, e também em relação ao desempenho.

A análise econômica pode revelar aspectos interessantes, mas merece ressalvas, já que a relação de custo beneficio entre os 6 tratamentos é flexível, pois os valores do insumos variam, o mercado da carne suína oscilam constantemente, além do que os produtos que contem probióticos em sua maioria são importados e portanto sofrem com as cotações do dólar. Porém, diante do banimento dos promotores de crescimento, deve-se levar em consideração a utilização de produtos alternativos, pois os custos podem ser secundários devido às constantes exigências internacionais, especialmente da União Europeia.

Conclui-se que, na fase de aleitamento, o tratamento com Lactobacillus reuteri e Bifidobacterium pseudolongum apresentou uma alternativa viável de utilização de probióticos pelo ganho diferencial obtido principalmente na primeira semana de vida dos leitões. $\mathrm{O}$ desempenho dos animais que receberam - Lactobacillus reuteri e Bifidobacterium pseudolongum na creche foi significativamente melhor em comparação aos demais tratamentos, 0 que indica esse probiótico poderia ser uma alternativa satisfatória de utilização O tratamento Controle Bacillus subtilis apresentou menor custo e pode representar uma alternativa satisfatória como inclusão na dieta do ponto de vista dos indicadores econômicos avaliados.

\section{REFERENCIAS}

\author{
ABE, F.; ISHIBASHI, N.; \\ SHIMAMURA, S. Effect of \\ administration of Bifidobacteria and \\ Lactic Acid Bacteria to newborn calves \\ and piglets. Journal of Dairy Science, \\ v.78, n.12, p.2838-2846,1995.
}

ABRAHÃO, A.A.F.; VIANNA, W.L.; CARVALHO, L.F.O.S.; MORETTI, A.S. Causas de mortalidade de leitões neonatos em sistema intensivo de produção de suínos. Brazilian Journal of Veterinary Research and Animal Science, v.41, p.86-91, 2004.

ALEXOPOULOS, C.; GEORGOULAKIS, I.E.; TZIVARA, A.; KYRIAKIS, C.S.; GOVARIS, A.; KYRIAKIS S.C. Field evaluation of the effect of a probiotic containing Bacillus licheniformis and Bacillus subtilis spores on the health "status", performance, and carcass quality of grower and finisher pigs. Journal of Veterinary Medicine, v.51, n.6,p.306-392, 2004.

BALAJI, R.; WRIGHT, K.J.; HILL, C.M.; DRITZ, S.S.; KNOPPEL, E.L.; 
Rev. Bras. Saúde Prod. Anim., Salvador, v.14, n.1, p.161-176 jan./mar., 2013 http://www.rbspa.ufba.br ISSN 15199940

MINTON, J.E. Acute phase responses of pigs challenged orally with Salmonella typhimurium. Journal of Animal

Science, v.78, p.1885-1891, 2000.

BRUNO, D. G. Efeito de um fito composto no desempenho de leitões submetidos ao desafio experimental com Salmonella typhimurium.

2008.137f. Dissertação (Mestre em Medicina Veterinária) - Faculdade de Medicina Veterinária e Zootecnia da Universidade de São Paulo, Pirassununga.

BUDIÑO, F.E.L.; THOMAZ, M.C.; KRONKA, R.N.; TUCCI, F.M.; FRAGA, A.L.; SCANDOLERA, A.J.; HUAYNATE, R.A.R.; NADAI, A.; CORREIA, R.C. Efeito da adição de probiótico e/ou prebiótico em dietas de leitões desmamados sobre o desempenho, incidência de diarréia e contagem de coliformes totais. Brazilian Journal of Veterinary Research and Animal Science, v.43, p.59-67, 2006.

BUTOLO, J.E. Qualidade de ingredientes na alimentação animal. Campinas: Colégio Brasileiro de Nutrição Animal, 2002. 430p.

BUTAYE, P.; DEVRIESE, L.A.; HAESEBROUCK, F. Antimicrobial growth promoters used in animal feed: effects of less well know antibiotics on Grampositive bacteria. Clinical Microbiology Reviews, v.16, n.2, p.175188, 2003.

CORRÊA, V. S.; CARAMORI JÚNIOR, J.G.; VIETES, F.M.; ABREU, J.G.; BARROS, D.S. Probiótico líquido para leitões lactentes em diferentes idades. Revista Brasileira de Saúde e Produção Animal [online], v.11, n.3, p.827-837, 2010.
FUKAYAMA, E.H.; BERTECHINI, A.G.; GERALDO, A.; KANJI KATO, R. SOLIS MURGAS, L.D. Extrato de orégano como aditivo em rações para frangos de corte. Revista Brasileira de Zootecnia, v.34, n.6, p.2316-2326, 2005.

LOUGHMILLER, J.A.; DRITZ, S.S.; NELSSEN, J.L.; TOKACH, M.D.; GOODBAND, R.D.; MOSER, S.A.; DE LA LLATA, M. Effects of Salmonella typhimurium Challenge on swine Growth, Nitrogen Balance, Insulin-like growth factor-I and Acute phase proteins. American Journal of Animal and Veterinary Sciences, v.2, n.1, p.11-22, 2007.

PARAZZI, L.J. Efeito da combinação de probióticos na dieta de leitões desafiados com Salmonella Typhimurium. 2010. 110p. Dissertação (Mestrado em Ciências) Faculdade de Medicina Veterinária e Zootecnia, Universidade de São Paulo, Pirassununga.

SAS Institute. SAS User's guide. Version 9.2. Cary, 2008.

SILVA, C.A.; HOSHI, E.H.; PACHECO, G.D.; BRIGANÓ, M.V. Avaliação de probióticos (Pediococcus acidilactici e Bacillus subtilis) após o desmame e efeitos no desempenho dos leitões, Semina: Ciências Agrárias, v.27, n.1, p.133-140, 2006.

STEWART, C.S.; CHESSON, A. Making sense of probiotics. Pig Veterinary Journal, v.31, p.11-33, 1993.

TURNER, J.L.; DRITZ, P.S.S.; MINTON, J.E. Review: Alternatives to conventional antimicrobials in swine diets. The Professional Animal Scientist, v.17, p.217-226, 2001. 
Rev. Bras. Saúde Prod. Anim., Salvador, v.14, n.1, p.161-176 jan./mar., 2013 http://www.rbspa.ufba.br ISSN 15199940

UTIYAMA, C.E.; OETTING, L.L.;

GIANI, P.A.; SANTOS RUIZ, U.;

MIYADA, V.S. Efeitos de

antimicrobianos, prebióticos,

probióticos e extratos vegetais sobre a

microbiota intestinal, a frequência de

diarréia e o desempenho de leitões

recém-desmamados. Revista Brasileira

de Zootecnia, v.35, n.6, p.2359-2367, 2006.

Data de recebimento: $24 / 09 / 2012$

Data de aprovação: 08/03/2013 